CZASOPISMO INŻYNIERII LĄDOWEJ, ŚRODOWISKA I ARCHITEKTURY JOURNAL OF CIVIL ENGINEERING, ENVIRONMENT AND ARCHITECTURE

JCEEA, t. XXXIV, z. 64 (3/I/17), lipiec-wrzesień 2017, s. 583-594, DOI: 10.7862/rb.2017.148

\author{
Roman BIJAK ${ }^{1}$ \\ Leszek CHODOR \\ Grzegorz KOLODZIEJ ${ }^{3}$
}

\title{
ZAKRZYWIONE PRECTY CIENKOŚCIENNE O PRZEKROJU BISYMETRYCZNYM
}

\begin{abstract}
W pracy przedstawiono geometrycznie nieliniową teorię wstępnie skręconych i zakrzywionych w przestrzeni prętów cienkościennych. W przykładach numerycznych analizowano pręty kołowe w zakresie liniowym dla dwóch warunków brzegowych: (1) podparcia widełkowego na obu końcach oraz (2) zamocowania na jednym końcu. Zastosowano 3-węzłowy element izoparametryczny z całkowaniem zredukowanym dla 2 punktów Gaussa. Porównania wyników numerycznych z rozwiązaniami analitycznymi pokazują niewielkie różnice między nimi. Z kolei, jeżeli dodatkowo przyjmiemy hipotezę Bernoulliego dla zginania i Własowa dla skręcania, z prezentowanej teorii można prosto wyprowadzić równania różniczkowe giętno-skrętnej utraty stateczności łuków kołowych.. Wzory na uogólnione odkształcenia są tak sformułowane, że możemy również w prosty sposób uwzględniać wpływ imperfekcji geometrycznych pręta.
\end{abstract}

Słowa kluczowe: zakrzywione pręty cienkościenne, przekrój bisymetryczny, aproksymacja drugiego rzędu skończonych obrotów przekroju, model Reissnera, sformułowanie izoparametryczne MES, rozwiązanie analityczne, pręty kołowe

\section{Wprowadzenie}

W prezentowanej pracy przedstawiono geometrycznie nieliniowe sformułowanie wariacyjne zakrzywionych prętów cienkościennych o bisymetrycznym przekroju poprzecznym. Przyjęto założenie, że obroty przekrojów poprzecznych w trakcie deformacji są opisane przez niezależne od przemieszczeń liniowych parametry a deformacja paczenia przez niezależną od skręcenia przekroju funkcję paczenia. Podobnie jak w pracy Bijak, Kołodziej [7], teoria jest ograniczona do zakresu małych obrotów (Reissner [5]). W dalszej części będziemy się po-

\footnotetext{
${ }^{1}$ Autor do korespondencji / corresponding author: Roman Bijak, Politechnika Świętokrzyska, Aleja Tysiąclecia P.P. 7, 25-314 Kielce, e-mail: r.bijak@wp.pl

${ }^{2}$ Leszek Chodor, Chodor-Projekt sp. z o.o., Aleja IX Wieków Kielc 6/3, 25-312 Kielce, 1ch@chodor-projekt.net

${ }^{3}$ Grzegorz Kołodziej, Kyotec Group, ul. Batalionu Platerówek 3, 03-308 Warszawa, e-mail: grzegorz.kolodziej @kyotecgrup.com
} 
woływać na wyniki pracy [7]. Samo sformułowanie teorii jest modyfikacją pracy Gruttmann i inni [6]. Po pierwsze przyjęto aproksymację drugiego rzędu ścisłej macierzy obrotu. Druga modyfikacja polega na tym, że możemy uogólnione odkształcenia wyznaczać za pomocą zmiennych związanych z układem odniesienia $\mathbf{e}_{i}$ (rys. 1.) pręta idealnego, tj. pręta o projektowanej krzywiźnie.

Pochodne byłyby wówczas liczone po współrzędnej $S_{0}$ pręta idealnego. Jest to podobne do teorii powłok o małej krzywiźnie Marguerre (Washizu [3]). Kosztem pewnej dokładności obliczeń prowadzi to do prostszego uwzględnienia imperfekcji geometrycznych w analizie numerycznej. W niniejszej pracy będziemy analizować pręty idealne. Wpływ wstępnych imperfekcji geometrycznych jest przedmiotem osobnego opracowania [4], korzystającego z formuł wprowadzonych w tej pracy $[1,2]$.

Rozpatrzmy pręt cienkościenny o przekroju bisymetrycznym pokazany na rysunku (rys. 1.). Do opisu deformacji wykorzystamy opis Lagrange'a. Wprowadzimy trzy lokalne układy współrzędnych kartezjańskich: (1) nieruchomy układ związany z fikcyjnym prętem o projektowanym zakrzywieniu (idealny); (2) układ odniesienia związany z przekrojem przed deformacją - pręt idealny z imperfekcjami geometrycznymi; (3) ruchomy układ lokalny związany z przekrojem $\mathrm{w}$ trakcie deformacji. W konfiguracji przed deformacją wektory bazowe są zbudowane w następujący sposób: wersor $\mathbf{T}$ jest styczny do krzywej odniesienia, będącej zbiorem punktów - środków ciężkości przekroju. Dwa wzajemnie prostopadłe wektory bazowe $\mathbf{A}_{2}, \mathbf{A}_{3}$ leżą w płaszczyźnie prostopadłej do krzywej odniesienia i pokrywają się z osiami głównymi przekroju.

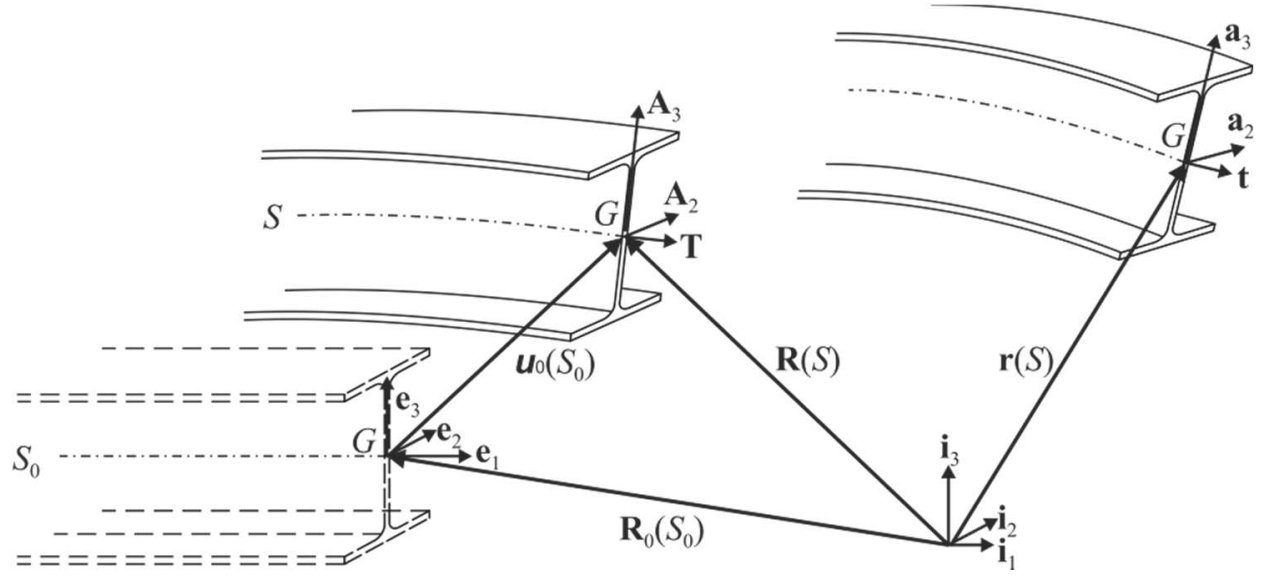

Rys. 1. Konfiguracja pręta zakrzywionego w przestrzeni

Fig. 1. Configuration of spatially curved rod

Wektory bazowe związane z przekrojem po deformacji $\left[\mathbf{t}, \mathbf{a}_{2}, \mathbf{a}_{3}\right]$ budujemy w analogiczny sposób, przy czym wersor $\mathbf{t}$ nie musi pozostawać styczny do krzywej odniesienia pręta po deformacji. 
W tak określonych układach możemy zdefiniować położenie dowolnego punktu materialnego pręta przed deformacją (rys. 1.):

$$
\mathbf{R}_{B}\left(S, X_{2}, X_{3}\right)=\mathbf{R}(S)+X_{2} \mathbf{A}_{2}(S)+X_{3} \mathbf{A}_{3}(S)
$$

oraz po deformacji:

$$
\mathbf{r}_{B}\left(S, X_{2}, X_{3}\right)=\mathbf{r}(S)+X_{2} \mathbf{a}_{2}(S)+X_{3} \mathbf{a}_{3}(S)-\omega\left(X_{2}, X_{3}\right) p(S) \mathbf{t}(S)
$$

gdzie:

$\mathbf{R}(S)$ - wektory wodzące punktu na krzywej odniesienia przed deformacją,

$\mathbf{r}(S)$ - jw. dla krzywej odniesienia po deformacji,

$S$ - długość łuku krzywej odniesienia przed deformacją,

$\omega\left(X_{2}, X_{3}\right)$ - zadana funkcja paczenia (np. współrzędna wycinkowa),

$p(S)$ - nieznana amplituda paczenia.

\section{Sformułowanie wariacyjne}

Składowe tensora odkształcenia Greena-Lagrange'a wyznaczamy analogicznie jak w pracy Gruttman i inni [6]:

$$
\mathbf{E}=\left[\begin{array}{c}
E_{11} \\
2 E_{12} \\
2 E_{13}
\end{array}\right]=\left[\begin{array}{c}
\left(\mathbf{g}_{1} \cdot \mathbf{g}_{1}-\mathbf{G}_{1} \cdot \mathbf{G}_{1}\right) / 2 \\
\mathbf{g}_{1} \cdot \mathbf{g}_{2}-\mathbf{G}_{1} \cdot \mathbf{G}_{2} \\
\mathbf{g}_{1} \cdot \mathbf{g}_{2}-\mathbf{G}_{1} \cdot \mathbf{G}_{2}
\end{array}\right]
$$

Podobnie kowariantne wektory bazowe w konfiguracji po deformacji [6]:

$$
\begin{aligned}
& \mathbf{g}_{1}=\partial \mathbf{r}_{B} / \partial S=\mathbf{r}^{(1)}+X_{2} \mathbf{a}_{2}^{(1)}+X_{3} \mathbf{a}_{3}^{(1)}-\omega p^{(1)} \mathbf{t}-\underline{\omega p \mathbf{t}^{(1)}} \\
& \mathbf{g}_{m}=\partial \mathbf{r}_{B} / \partial X_{m}=\mathbf{a}_{m}-\omega_{, m} p \mathbf{t},(m=2,3)
\end{aligned}
$$

gdzie:

$f^{(\mathrm{k})}=\partial^{\mathrm{k}} f / \partial S^{\mathrm{k}}-k$-ta pochodna po współrzędnej $S$,

$\omega_{, m}$ - pochodna cząstkowa $\omega\left(X_{2}, X_{3}\right)$ po współrzędnej $X_{m}(m=2,3)$.

W dalszych analizach pomijamy podkreślony wyraz we wzorze (4a). Dla konfiguracji przed deformacją kowariantne wektory bazowe $\mathbf{G}_{i}$ wyznaczamy zamieniając w (4a, b) $\mathbf{r}_{B}$ na $\mathbf{R}_{B}$ [6]. Przyjęto definicje sił przekrojowych z wcześniejszej pracy [7], zmieniając niektóre oznaczenia. Na określenie bimomentu zamiast $B_{w}$ przyjęto $M_{w}$, natomiast $T$ odnosi się do momentów skręcających. Należy podkreślić, że parametry uogólnionych odkształceń $b(S), k_{2}(S), k_{3}(S)$ nie są rzeczywistymi krzywiznami (ponieważ różniczkujemy po długości łuku krzywej odniesienia przed deformacją) a jedynie je aproksymują. Składowe wektorów 
bazowych po deformacji [t, a2, a $a_{3}$ (wzór 16) wyznaczono w sposób przybliżony, za pomocą aproksymacji drugiego rzędu ścisłej macierzy obrotu (wzór (4.2) [7]).

\subsection{Praca sił wewnętrznych w zakresie sprężystym}

Pracę sił wewnętrznych rozdzielamy na część wynikającą z odkształceń osiowych $\left(\delta \Pi_{1}\right)$ i odkształceń stycznych $\left(\delta \Pi_{2}\right)$ :

$$
\begin{aligned}
& \delta \Pi=\delta \Pi_{1}+\delta \Pi_{2} \\
& \delta \Pi_{1}=\int_{L}\left(N \delta e+M_{2} \delta k_{2}+M_{3} \delta k_{3}+M_{w} \delta \chi\right) d S \\
& \delta \Pi_{2}=\int_{L} T_{s v} \delta b d S+\int_{L}\left(V_{2} \delta \gamma_{2}+V_{3} \delta \gamma_{3}+T_{w} \delta p_{w}\right) d S
\end{aligned}
$$

Najpierw sformułujemy zależności pomiędzy siłami przekrojowymi a uogólnionymi odkształceniami, wynikającymi z odkształceń osiowych. Dla sprężystego, izotropowego materiału możemy je zapisać w formie macierzowej:

$$
\left[\begin{array}{c}
N \\
M_{2} \\
M_{3} \\
M_{w}
\end{array}\right]=\left[\begin{array}{cccc}
E A & 0 & 0 & 0 \\
& E I_{22} & 0 & 0 \\
& & E I_{33} & 0 \\
s y m m & & & E I_{w}
\end{array}\right]\left[\begin{array}{c}
e \\
k_{2}-K_{2} \\
k_{3}-K_{3} \\
\chi
\end{array}\right]
$$

gdzie: $E$ - moduł sprężystości podłużnej,

$A$ - pole przekroju poprzecznego,

$N, e-$ siła osiowa i odpowiadające jej uogólnione odkształcenie (9a),

$I_{22}, I_{33}$ - główne momenty bezwładności odpowiednio względem osi 2, 3,

$M_{2}, M_{3}$ - momenty zginające odpowiednio względem osi 2, 3,

$K_{2}, K_{3}$ - krzywizny przed deformacją (13b),

$k_{2}, k_{3}$ - quasi-krzywizny po deformacji (13a),

$I_{w}$ - moment bezwładności giętno-skrętny,

$M_{w}, \chi$ - bimoment i odpowiadające mu uogólnione odkształcenie (9b).

$$
e=\gamma_{1}-\Gamma_{1}+i_{p}^{2}\left(b^{2}-B^{2}\right) / 2, \quad \chi=-p^{(1)}
$$

gdzie: $i_{p}=\left(I_{p} / \mathrm{A}\right)^{0,5}$ - biegunowy promień bezwładności,

$I_{p}=I_{22}+I_{33}-$ biegunowy moment bezwładności,

$\Gamma_{1}, \gamma_{1}$ - parametry odkształcenia wyznaczone w p. 2.2,

$B, b$ - wstępne skręcenie przekroju i quasi-skręcenie po deformacji (13a, b).

Całkowity moment skręcający $T$ rozdzielamy na moment skręcania swobodnego St. Venanta $T_{s v}$ i moment skręcania skrępowanego $T_{w}$ :

$T=T_{s v}+T_{w}$ 
W przypadku sprężystego, izotropowego materiału otrzymujemy:

$$
\begin{array}{ll}
T_{s v}=G I_{T}(b-B), & {\left[\begin{array}{c}
V_{2} \\
V_{3} \\
T_{w}
\end{array}\right]=\left[\begin{array}{ccc}
G A_{2} & 0 & 0 \\
0 & G A_{3} & 0 \\
0 & 0 & G D_{w}
\end{array}\right]\left[\begin{array}{c}
\gamma_{2}-\Gamma_{2} \\
\gamma_{3}-\Gamma_{3} \\
p_{w}
\end{array}\right]} \\
D_{w}=I_{p}-I_{T}, \quad I_{T}=\int_{A}\left[\left(X_{2}-\omega_{, 3}\right)^{2}+\left(X_{3}+\omega_{, 2}\right)^{2}\right] d A
\end{array}
$$

gdzie: $G$ - moduł sprężystości poprzecznej,

$A_{2}, A_{3}$ - pole przekroju czynnego przy ścinaniu wzdłuż osi 2,3 ,

$V_{2}, V_{3}$ - siły poprzeczne na kierunku osi 2,3 ,

$\gamma_{2}, \gamma_{3}, \Gamma_{2}, \Gamma_{3}$ - parametry odkształcenia od sił poprzecznych (14a, b),

$I_{T}$ - moment bezwładności skręcania St. Venanta (12b),

$D_{w}$ - moment bezwładności skręcania skrępowanego (12a).

\subsection{Uogólnione odkształcenia w zakresie małych obrotów}

Uogólnione odkształcenia wyznaczamy ze wzorów [6, 7]:

$$
\begin{array}{ll}
{\left[\begin{array}{c}
b(S) \\
k_{2}(S) \\
k_{3}(S)
\end{array}\right]=\left[\begin{array}{c}
\mathbf{a}_{2}^{(1)} \cdot \mathbf{a}_{3} \\
\mathbf{a}_{3}^{(1)} \cdot \mathbf{t} \\
-\mathbf{a}_{2}^{(1)} \cdot \mathbf{t}
\end{array}\right],} & {\left[\begin{array}{c}
B(S) \\
K_{2}(S) \\
K_{3}(S)
\end{array}\right]=\left[\begin{array}{c}
\mathbf{A}_{2}^{(1)} \cdot \mathbf{A}_{3} \\
\mathbf{A}_{3}^{(1)} \cdot \mathbf{T} \\
-\mathbf{A}_{2}^{(1)} \cdot \mathbf{T}
\end{array}\right]} \\
{\left[\begin{array}{l}
\gamma_{1}(S) \\
\gamma_{2}(S) \\
\gamma_{3}(S)
\end{array}\right]=\left[\begin{array}{l}
\mathbf{r}^{(1)} \cdot \mathbf{t} \\
\mathbf{r}^{(1)} \cdot \mathbf{a}_{2} \\
\mathbf{r}^{(1)} \cdot \mathbf{a}_{3}
\end{array}\right],} & {\left[\begin{array}{l}
\Gamma_{1}(S) \\
\Gamma_{2}(S) \\
\Gamma_{3}(S)
\end{array}\right]=\left[\begin{array}{c}
\mathbf{R}^{(1)} \cdot \mathbf{T} \\
\mathbf{R}^{(1)} \cdot \mathbf{A}_{2} \\
\mathbf{R}^{(1)} \cdot \mathbf{A}_{3}
\end{array}\right]} \\
p_{w}=(b-B)-p &
\end{array}
$$

Ograniczymy się do zakresu małych obrotów przekroju, ponieważ stan graniczny użytkowania konstrukcji budowlanych wyklucza w praktyce przypadki skończonych obrotów. Na podstawie [7] wektory bazowe po deformacji możemy aproksymować wzorami:

$$
\begin{aligned}
& \mathbf{t}=\left(1-\theta_{2}^{2} / 2-\theta_{3}^{2} / 2\right) \mathbf{T}+\theta_{3} \mathbf{A}_{2}-\theta_{2} \mathbf{A}_{3} \\
& \mathbf{a}_{2}=\left(-\theta_{3}+\theta_{2} \varphi\right) \mathbf{T}+\left(1-\theta_{3}^{2} / 2+\varphi^{2} / 2\right) \mathbf{A}_{2}+\left(\varphi+\theta_{2} \theta_{3} / 2\right) \mathbf{A}_{3} \\
& \mathbf{a}_{3}=\left(\theta_{2}+\theta_{3} \varphi\right) \mathbf{T}+\left(-\varphi+\theta_{2} \theta_{3} / 2\right) \mathbf{A}_{2}+\left(1-\theta_{2}^{2} / 2-\varphi^{2} / 2\right) \mathbf{A}_{3}
\end{aligned}
$$

Podstawiając (16) do (13a, b), (14a, b) otrzymujemy wzory na uogólnione odkształcenia (jawne wyrażenia przedstawiono w [7]). 
Poniżej podajemy wybrany wzór, z którego będziemy korzystać w p. 3.2 przy rozpatrywaniu stateczności początkowej łuków kołowych. W przypadku braku wstępnego skręcenia $(B=0)$ otrzymujemy [7]:

$$
k_{2}-K_{2}=\theta_{2}^{(1)}+K_{3} \varphi+\theta_{3}^{(1)} \varphi-K_{2}\left(\theta_{3}^{2} / 2+\varphi^{2} / 2\right)+K_{3} \theta_{2} \theta_{3} / 2
$$

Reissner [5] i Gruttman i inni [6] w modelu obliczeniowym wyznaczają $\gamma_{1}(S)$ bezpośrednio z (14a). W prezentowanej pracy przyjęto natomiast aproksymację $\mathbf{s} \cdot \mathbf{t} \approx 1$, zastosowaną w programie ABAQUS [12] (s jest wersorem stycznym do krzywej odniesienia w konfiguracji po deformacji). Podstawiając do wzoru na $\gamma_{1}(S)$ s zamiast $\mathbf{t}$ otrzymujemy:

$$
\gamma_{1}(S)=\left|\mathbf{r}^{(1)}\right|
$$

gdzie: $|\cdot|-$ długość wektora, $\mathbf{s}=\mathbf{r}^{(1)} /\left|\mathbf{r}^{(1)}\right|$.

\section{Statyka liniowa i stateczność początkowa pręta o projektowanym zakrzywieniu}

Jeżeli rozpatrujemy pręt o projektowanym zakrzywieniu, bez imperfekcji geometrycznych to z (14b) otrzymujemy następujące zależności:

$$
\Gamma_{1}(S)=\left|\mathbf{R}^{(1)}\right|=1, \quad \Gamma_{2}(S)=\Gamma_{3}(S)=0
$$

\subsection{Analiza liniowa prętów prostych i kołowych}

Rozpatrzmy pręt kołowy zakrzywiony w płaszczyźnie prostopadłej do wersora $\mathbf{A}_{3}$ (rys. 1.). W tym przypadku $B=K_{2}=0, K_{3}=1 / R_{3}$ ( $R_{3}$ jest promieniem krzywizny). Do obliczeń przyjmiemy liniowe części uogólnionych odkształceń [7]:

$$
\left[\begin{array}{l}
e \\
\gamma_{2} \\
\gamma_{3}
\end{array}\right]=\left[\begin{array}{c}
u^{(1)}-K_{3} v_{2} \\
v_{2}^{(1)}+K_{3} u-\theta_{3} \\
v_{3}^{(1)}+\theta_{2}
\end{array}\right], \quad\left[\begin{array}{c}
b \\
k_{2} \\
k_{3}-K_{3}
\end{array}\right]=\left[\begin{array}{c}
\varphi^{(1)}-K_{3} \theta_{2} \\
\theta_{2}^{(1)}+K_{3} \varphi \\
\theta_{3}^{(1)}
\end{array}\right]
$$

Uwzględniając $(8,11 \mathrm{a}, \mathrm{b})$ praca sił wewnętrznych $(6,7)$ wyraża się odpowiednio za pomocą wzorów (21), (22):

$$
\begin{aligned}
& \delta \Pi_{1}=\int_{L}\left(\delta e E A e+\delta k_{2} E I_{22} k_{2}+\delta k_{3} E I_{33}\left(k_{3}-K_{3}\right)+\delta p^{(1)} E I_{w} p^{(1)}\right) d S \\
& \delta \Pi_{2}=\int_{L} \delta b G I_{T} b d S+\int_{L}\left(\delta \gamma_{2} G A_{2} \gamma_{2}+\delta \gamma_{3} G A_{3} \gamma_{3}+\delta p_{w} G D_{w} p_{w}\right) d S
\end{aligned}
$$

Do obliczeń numerycznych przyjęto 3-wezłowy element izoparametryczny. 
Uogólnione przemieszczenia punktów na krzywej odniesienia przed deformacją $\left(u, v_{2}, v_{3}, \varphi, \theta_{2}, \theta_{3}, p\right)$ są aproksymowane następującymi funkcjami kształtu (rys. 2a):

$$
N_{1}(\xi)=(\xi / 2)(\xi-1), \quad N_{2}(\xi)=(\xi / 2)(\xi+1), \quad N_{3}(\xi)=1-\xi^{2} \quad(23 \mathrm{a} \div \mathrm{c})
$$

gdzie: $\xi \in[-1,+1]-$ wspótrzędna naturalna,

Po uwzględnieniu zależności $S=\left(L_{e} / 2\right)(\xi+1)$ (rys. 2a) otrzymujemy wyrażenia na pochodne po $S$ :

$$
f^{(1)}=\left(2 / L_{e}\right) \partial f / \partial \xi
$$

W celu uniknięcia tzw. „blokady” ścinania i skręcania, zastosowano całkowanie zredukowane dla dwóch punktów Gaussa (Hughes [9]).

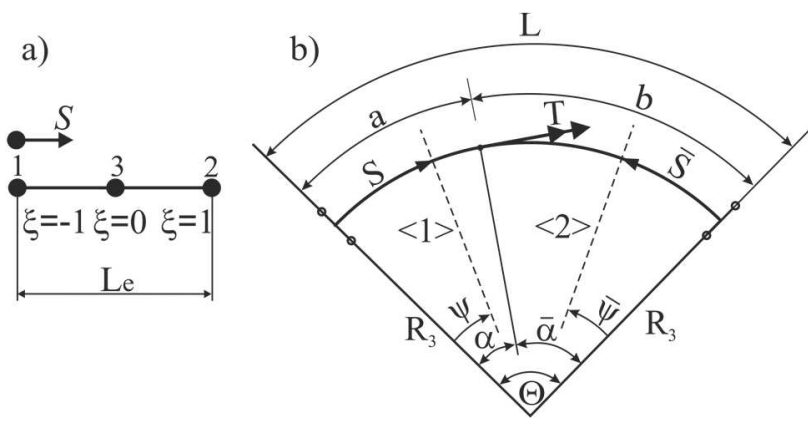

c)

Rys. 2. a) 3-wezłowy element izoparametryczny, b) pręt kołowy zakrzywiony w planie - widok $\mathrm{z}$ góry c) pręt kołowy zakrzywiony w planie - widok z boku

Fig. 2. a) 3-node isoparametric finite element, b) circular beam (curved in plane) - top view c) circular beam (curved in plane) - side view

Zaprezentowane sformułowanie zaimplementowano, jako program MES działający w środowisku Maxima [13]. Przeprowadzono liczne testy numeryczne weryfikujące poprawność programu, porównując otrzymane wyniki z uzyskanymi w innych, sprawdzonych pakietach MES [12] lub z rozwiązaniami analitycznymi znanymi z literatury (Dąbrowski [10]).

\section{Przykład 1}

W pierwszym przykładzie analizujemy łuk kołowy podparty widełkowo na końcach, o następujących parametrach geometrycznych (rys. 2.): $L=300 \mathrm{~cm}$, $R_{3}=430 \mathrm{~cm}, \Theta=0,6981 \mathrm{rad}, a=b=L / 2$. Pręt jest obciążony skupionym momentem skręcającym o wartości $T=150 \mathrm{kNcm}$. Łuk podzielono na 10 elementów skończonych. Do obliczeń przyjęto profil IPE200.

Analogicznie jak w pracy [10] wprowadźmy parametry opisujące geometrię pręta (rys. 2b): 


$$
\begin{aligned}
& \psi=\frac{S}{R_{3}}, \quad \bar{\psi}=\frac{\bar{S}}{R_{3}}, \quad \Theta=\frac{L}{R_{3}}, \quad \alpha=\frac{a}{R_{3}}, \quad \bar{\alpha}=\frac{b}{R_{3}} \\
& k=\sqrt{\frac{G I_{T}}{E I_{w}}}, \quad \eta=\frac{1}{1+\left(k R_{3}\right)^{2}}
\end{aligned}
$$

Otrzymane wyniki MES zestawiono z rozwiązaniem analitycznym zaprezentowanym w pracy Dąbrowskiego [10], w której przedstawiono odpowiednio funkcje bimomentu oraz momentu skręcającego (rys. 3-6):

$$
\begin{aligned}
& M_{w, 1}(S)=\frac{T(1-\eta)}{k} \frac{\sinh k b}{\sinh k L} \sinh k S+T \eta R_{3} \frac{\sin \bar{\alpha}}{\sin \Theta} \sin \psi \\
& T_{1}(S)=T \frac{\sin \bar{\alpha}}{\sin \Theta} \cos \psi \\
& M_{w, 2}(\bar{S})=\frac{T(1-\eta)}{k} \frac{\sinh k a}{\sinh k L} \sinh k \bar{S}+T \eta R_{3} \frac{\sin \alpha}{\sin \Theta} \sin \bar{\psi} \\
& T_{2}(\bar{S})=-T \frac{\sin \alpha}{\sin \Theta} \cos \bar{\psi}
\end{aligned}
$$

Gdy $R_{3}$ dąży do nieskończoności otrzymujemy wzory dla prętów prostych, zawarte w pracy [8]. Poniżej przedstawiono porównanie wykresów otrzymanych z analizy MES i równań $(27,28)$ dla bimomentu (rys. 3.) i momentu skręcającego.

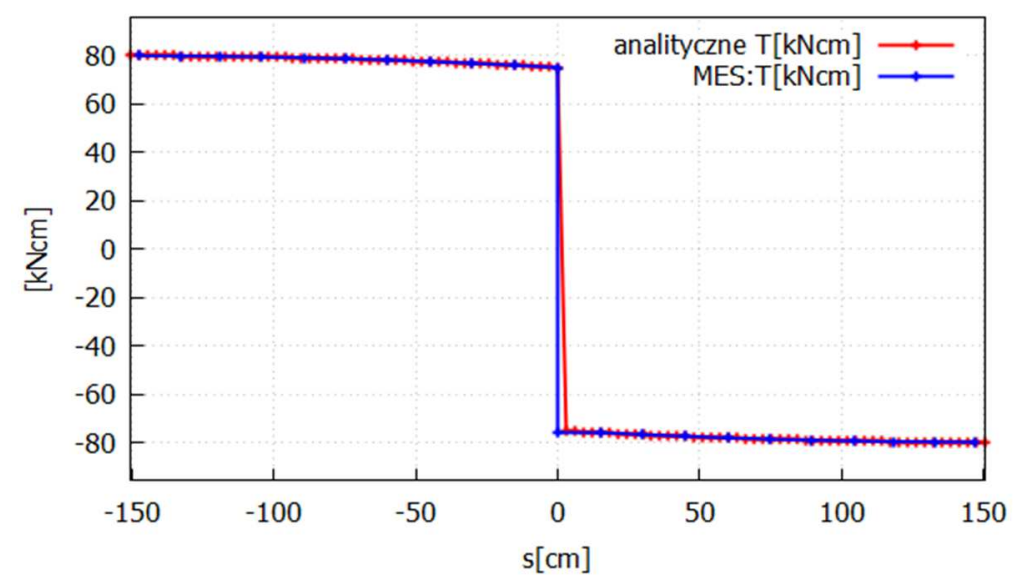

Rys. 3. Wykres momentu skręcającego - porównanie wyników MES i wg wzorów analitycznych, na podstawie [10]

Fig. 3. Torsion chart - comparison of MES results and analytic approach, based on [10] 


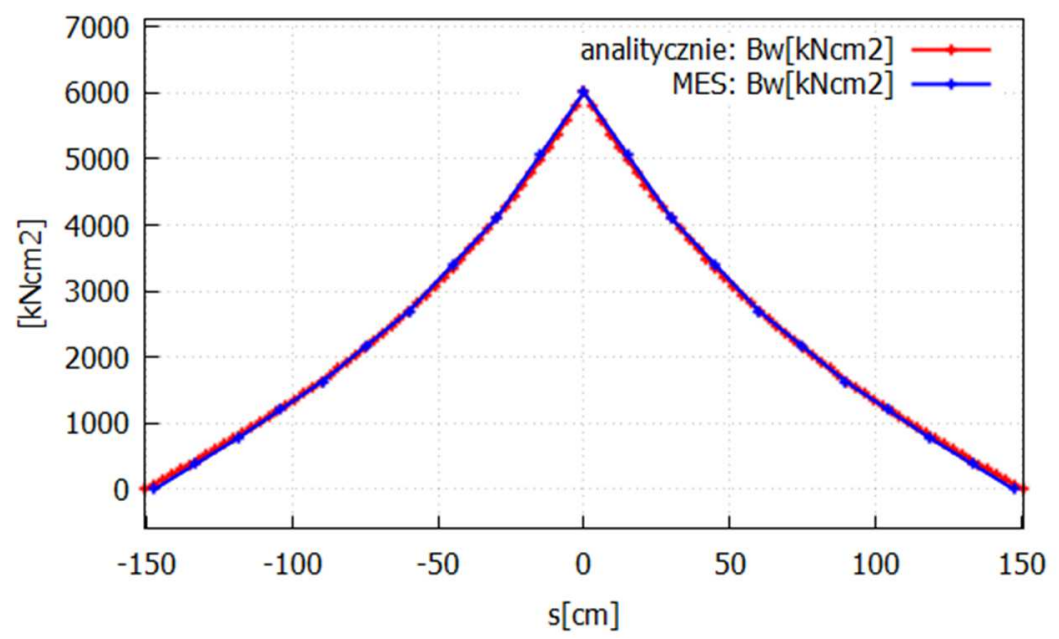

Rys. 4. Wykres bimomentu - porównanie wyników MES i wg wzorów, na podstawie [10]

Fig. 4. Bimoment chart - comparison of MES results and analytic approach, based on [10]

\section{Przykład 2}

Rozpatrzmy wspornikowy luk kołowy o parametrach geometrycznych (rys. 2.): $L=392,7 \mathrm{~cm}, R_{3}=500 \mathrm{~cm}, \Theta=\pi / 4, a=b=L / 2$. Pręt jest obciążony skupionym momentem skręcającym o wartości $T=100 \mathrm{kNcm}$. Łuk podzielono na 10 elementów skończonych. Przyjęto profil IPE200 jak w przykładzie 1.

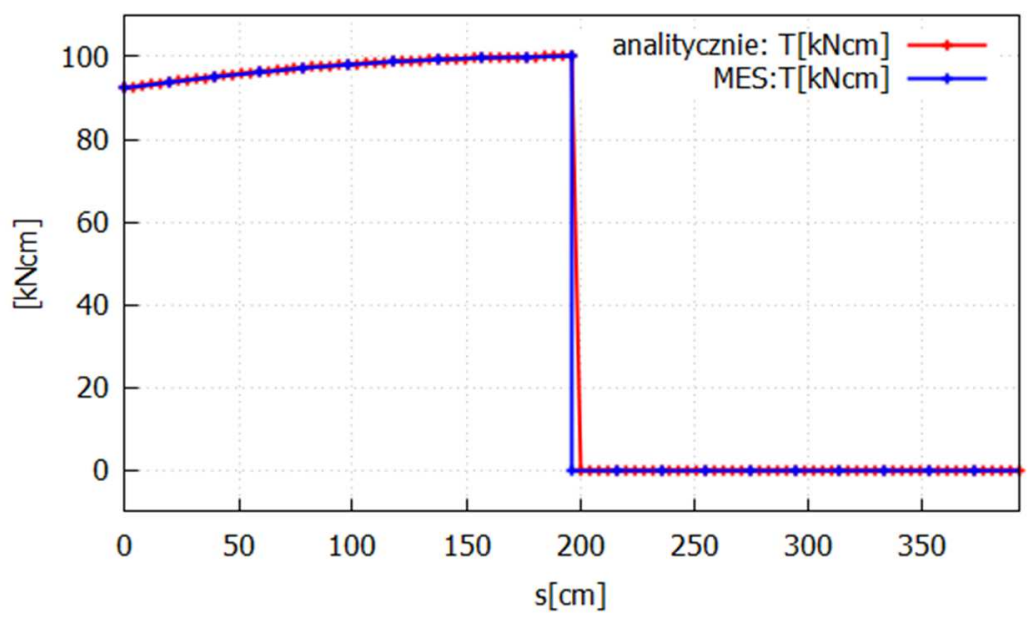

Rys. 5. Wykres całkowitego momentu skręcającego - porównanie wyników MES i wg wzorów analitycznych, na podstawie [10]

Fig. 5. Torsion chart - comparison of MES results and analytic approach, based on [10] 


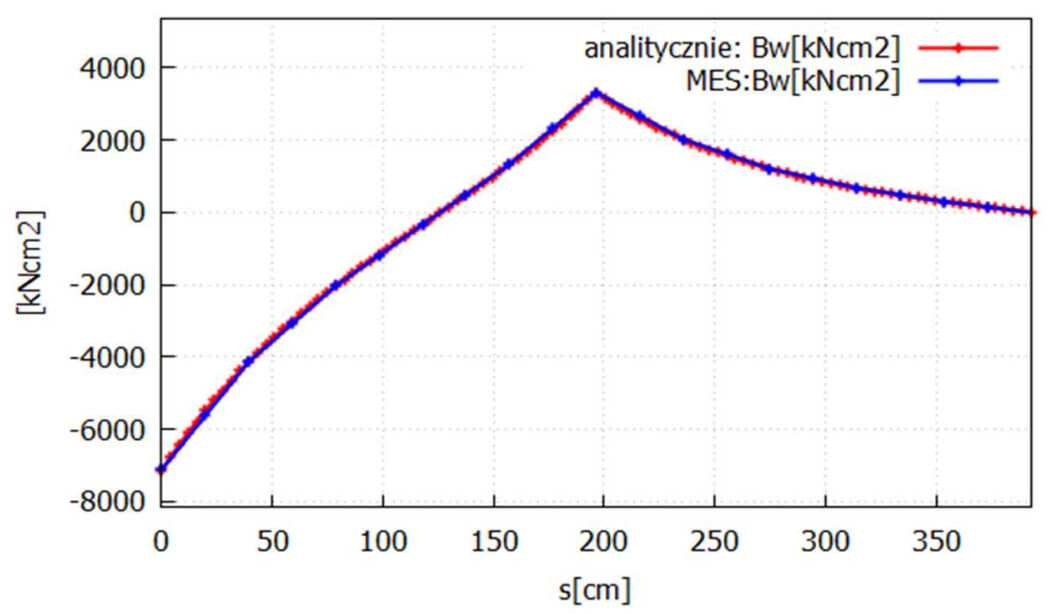

Rys. 6. Wykres bimomentu - porównanie wyników MES i wg wzorów analitycznych, na podstawie [10]

Fig. 6. Bimoment chart - comparison of MES results an analytic approach, based on [10]

Widoczna jest bardzo dobra zgodność wyników otrzymanych z programu MES opracowanego na podstawie sformułowania przedstawionego $\mathrm{w}$ niniejszej pracy oraz rozwiązań analitycznych z pracy [10]. W analizowanych przykładach względne różnice nie przekraczają $0,25 \%$.

\subsection{Giętno-skrętna utrata stateczności prętów kołowych}

Rozpatrzmy pręt kołowy zakrzywiony w płaszczyźnie prostopadłej do wersora $\mathbf{A}_{2}$ (rys. $1, B=K_{3}=0, K_{2}=1 / R_{2}$ ). Pomijamy wpływ przemieszczeń w płaszczyźnie łuku $\left(u=v_{3}=\theta_{2}=0\right)$. Warunek giętno-skrętnej utraty stateczności cienkościennych prętów kołowych możemy zapisać w formie:

$$
\delta \Pi_{b}=\delta \Pi_{b 1 L}+\delta \Pi_{b 2 L}+\delta \Pi_{b G}=0
$$

Wyrazy w równaniu (29) zależne od liniowej części uogólnionych odkształceń przedstawimy następująco:

$$
\begin{aligned}
& \delta \Pi_{b 1 L}=\int_{L}\left(\delta k_{3 L} E I_{33} k_{3 L}+\delta p^{(1)} E I_{w} p^{(1)}\right) d S \\
& \delta \Pi_{b 2 L}=\int_{L} \delta b_{L} G I_{T} b_{L} d S+\int_{L}\left(\delta \gamma_{2 L} G A_{2} \gamma_{2 L}+\delta p_{w L} G D_{w} p_{w L}\right) d S \\
& k_{3 L}=\theta_{3}^{(1)}-K_{2} \varphi \\
& b_{L}=\varphi^{(1)}+K_{2} \theta_{3}, \quad \gamma_{2 L}=-\theta_{3}+v_{2}^{(1)}, \quad p_{w L}=b_{L}-p
\end{aligned}
$$


Wzory $(32 a \div d)$ otrzymano na podstawie zależności wyprowadzonych w pracy Bijak, Kołodziej [7]. Ostatni człon równania (29) wynika z efektów nieliniowych:

$$
\begin{aligned}
& \delta \Pi_{b G}=\int_{L}\left(N \delta e_{N}+M_{2} \delta k_{2 N}\right) d S \\
& e_{N}=\left(v_{2}^{(1)}\right) / 2+i_{p}^{2} b_{L}^{2} / 2, \quad k_{2 N}=\theta_{3}^{(1)} \varphi-K_{2}\left(\theta_{3}^{2} / 2+\varphi^{2} / 2\right)
\end{aligned}
$$

gdzie: $e_{N}, k_{2 N}-$ są nieliniowymi częściami uogólnionych odkształceń $e, k_{2}$.

Jeżeli przyjmiemy hipotezę Bernoulliego dla zginania i Własowa dla skręcania otrzymamy następujące wzory na uogólnione odkształcenia [7]:

$$
\begin{array}{ll}
\gamma_{2 L}=0, & p_{w L}=0 \\
\theta_{3}=v_{2}^{(1)}, & k_{3 L}=v_{2}^{(2)}-\varphi / R_{2}, \quad p=b_{L}=\varphi^{(1)}+v_{2}^{(1)} / R_{2}
\end{array}
$$

$(36 a \div c)$

Całkując przez części równanie (29), zmodyfikowane za pomocą zależności (35), (36), otrzymujemy równania różniczkowe odpowiadające równaniom (17), (18) w pracy Pi, Bradford [11].

\section{Wnioski}

W 3-węzłowym elemencie izoparametrycznym całkowanie zredukowane dla dwóch punktów Gaussa (Hughes [9]) pozwala uniknąć tzw. „blokady” ścinania i skręcania. Dzięki temu rozwiązanie numeryczne ma bardzo dobrą zbieżność do wyników analitycznych. Prezentowane sformułowanie jest bardzo elastyczne i można je w prosty sposób wykorzystać do rozwiązania różnych szczegółowych zagadnień związanych z mechaniką prętów cienkościennych (np. stateczności początkowej łuków kołowych).

W poprzedniej pracy autorów [7] przyjęto wzory na odkształcenia na podstawie teorii używanej przez system Abaqus [12], upraszczając je dla zakresu małych obrotów przekroju. W przypadku pręta idealnego prezentowane sformułowanie pokrywa się z wynikami pracy [7]. Ma jednak tę przewagę nad poprzednim, że na jej podstawie można w prosty sposób analizować pręty z imperfekcjami geometrycznymi. W tym przypadku $\Gamma_{1}\left(S_{0}\right) \neq 1, \Gamma_{2}\left(S_{0}\right) \neq 0, \Gamma_{3}\left(S_{0}\right) \neq 0$ (por. (19)).

\section{Literatura}

[1] Chodor L., Bijak R.: Stochastic finite element analysis of 3D thin-walled structures, Short Papers, 20th International Conference on Computer Methods in Mechanics CMM2013 - Poznań, 2013, MS06-1, MS06-2.

[2] Chodor L.: Imperfekcyjna teoria niezawodności, w przygotowaniu do druku w Wydawnictwie Naukowym PWN. 
[3] Washizu K.: Variational Methods in Elasticity and Plasticity. Pergamon Press, New York, 3 edition, 1982.

[4] Bijak R., Chodor L., Kołodziej G., Kowal Z.: Zakrzywione pręty cienkościenne z imperfekcjami geometrycznymi, w przygotowaniu do Archives of Civil Engineering.

[5] Reissner E.: On finite deformations of space-curved beams, Journal Appl. Math. Phys. (ZAMP), vol. 32, 1981, pp. 734-744.

[6] Gruttmann F., Sauer R., Wagner W.: Theory and numerics of three-dimensional beams with elastoplastic material behaviour, Int. J. Numer. Methods Engrg., vol. 48, 2000, pp. 1675-1702.

[7] Bijak R., Kołodziej G.: On finite deformations of spatially curved bisymmetric thinwalled rods, Archives of Civil Engineering, vol. 62(1), Mar 2016, pp. 25-36.

[8] Bijak R., Kołodziej G.: Zginanie i skręcanie belek o przekroju mono-symetrycznym, Czasopismo Inżynierii Lądowej, Środowiska i Architektury - Journal of Civil Engineering, Environment And Architecture, JCEEA, t. XXXIII, z. 63 (1/I/16), styczeńmarzec 2016, s. 315-322, DOI: 10.7862/rb.2016.37.

[9] Hughes, T.J.R.: The Finite Element Method. Linear Static and Dynamic Finite Element Analysis, Prentice-Hall, 1987.

[10] Dąbrowski R.: Gekrümte dünnwandige Träger. Theorie und Berechnung. Springer Verlag, Berlin 1968.

[11] Pi Y.L., Bradford M.A.: Elastic flexural-torsional buckling of continuously restrained arches, Int. J. Solids Struct., 39(8), 2002, pp. 2299-322.

[12] Abaqus 6.11, Theory Manual, Dassault Systemes, 2011.

[13] Maxima, A Computer Algebra System, http://maxima.sourceforge.net (10-04-2017).

\section{BISYMMETRIC CURVED THIN-WALLED RODS}

\section{S u m m a r y}

In the paper it was presented nonlinear theory of initially twisted and bended thin walled rods in three dimensional space. Theory was basis for implementation of computer program, which employs 3-node isoparametric finite element with reduced numerical integration (Gaussian integration at 2 points). In numerical examples, circular rods were analyzed in a linear range for two boundary conditions: 1) circular arch with fork-alike supports at the ends 2) fully restrained cantilever. Result were compared then with analytic solutions and good consistency was observed. On the other hand, additional assumption of Bernouli hypothesis for bending and Wlasov theory for twisting allows for easy derivation of differential equations of lateral-torsional buckling for circular arches. Expressions for generalized strains are formulated in a manner which allows taking into consideration influence of geometric imperfections of the rods in the analysis.

Keywords: space-curved thin-walled rods, bisymmetric cross-sections, second-order approximations of finite rotations, Reissner model, isoparametric formulation, circular arch, analytic solution

Przestano do redakcji: 20.04.2017 r.

Przyjęto do druku: 01.09.2017 r. 